\title{
Instructional effects in memory for frequency of occurrence
}

\author{
NORMAN R. ELLIS and ROLAND L. PALMER \\ University of Alabama, Tuscaloosa, Alabama
}

\begin{abstract}
The effects of instructions on memory for frequency were assessed, using a vigilance cover task designed to minimize strategic or effortful processing. Subjects performed a 1,250-item (words and numbers) vigilance task and then made frequency estimates on some of the words. The three instruction conditions were intentional, incidental, and nonspecific. Frequency estimates were most accurate and vigilance performance was lowest following nonspecific memory instructions. The findings support an indirect frequency coding model.
\end{abstract}

Hasher and Zacks $(1979,1984)$ hypothesized that certain stimulus attributes are encoded automatically. Of these, frequency of occurrence has received most attention. Hasher and Zacks proposed a number of criteria for categorizing processes as automatic or effortful. The criterion that is perhaps most central to their position is that instructions affect effortful but not automatic processing. An automatic process requires no attentional allocaton and cannot be strategically facilitated.

The findings on instructional effects are mixed. Some have reported more accurate frequency estimates with intentional than with incidental instructions (Fisk \& Schneider, 1984; Greene, 1984, 1986; Zacks, Hasher, \& Sanft, 1982); others have reported no effects due to instructions (Attig \& Hasher, 1980; Flexer \& Bower, 1975; Hasher \& Chromiak, 1977; Hasher \& Zacks, 1979; Kausler \& Puckett, 1980; Rose \& Rowe, 1976). More recently, Naveh-Benjamin and Jonides (1986) found instructional effects with 1- and 2-sec stimulus exposure rates, but not with a $4-\mathrm{sec}$ rate.

Greene (1986) found more accurate frequency estimates with intentional instructions, but this occurred only when the instructions stressed the importance of remembering frequency. Clearly, the conditions under which instructional effects do and do not occur are unsettled.

The present experiment was designed to shed further light on the issue. A vigilance paradigm was used as a cover task that required subjects to monitor an extended series of numbers and words under one of three types of memory instructions: intentional, incidental, and nonspecific. The target was a number or word repeated in adjacent serial positions. The item exposure rate was 1

This research was supported by Grant HD 15558 to the first author from the National Institute of Child Health and Human Development. The data collection was sponsored by the Air Force Office of Scientific Research/AFSC, United States Air Force, under Contract F 49620-85C-0013. The United States government is authorized to reproduce and distribute reprints for governmental purposes notwithstanding any copyright notation hereon. Requests for reprints should be sent to Norman R. Ellis, Department of Psychology, University of Alabama, P. O. Box 2968, Tuscaloosa, AL 35487-2968. or $2 \mathrm{sec}$. The list consisted of 1,250 items, and the likelihood of subjects' counting frequencies or using similar strategies was remote. The task also provided genuine incidental conditions. Instructional effects, should they occur, would seem attributable to indirect effects on the coding of individual items.

\section{METHOD}

\section{Subjects}

Air Force enlisted men in their sixth day of basic training at Lackland Air Force Base (Texas) served as subjects. The assignment of subjects to the six groups was random, but inadvertently unequal. There were 33,40 , and 41 of the intentional, nonspecific, and incidental instruction conditions, respectively, at a 1 -sec-per-item presentation rate. In the 2 -sec groups, the numbers were 29,44 , and 44 , respectively.

\section{Procedure}

The vigilance cover task was presented on an 11-in. CRT interfaced with a computer. The target was a number (1 or 25$)$ or word repeated in adjacent positions in the list. The subjects responded by pressing keys on the computer keyboard. To be counted as a "hit," the response had to occur during the exposure of the word or number. Following a 60-item practice session, subjects were given a 1,250-item task consisting of 445 three-digit numbers shown once each, 40 numbers (targets) shown twice in a row, 40 words (targets) shown twice in a row, and 525 words (AA and A words from the Thorndike \& Lorge, 1944, list) to be judged for frequency of occurrence. An additional 120 numbers served as a buffer at the end of the list. The 525 words consisted of 140 unique words: 35 were shown once, 35 twice, 35 four times, and 35 eight times. These words were never target words and they were not repeated within five-trial blocks. No more than three consecutive items were all numbers or all words. Otherwise the items were randomly arranged throughout the list. The items were each exposed for 1 or $2 \mathrm{sec}$. A $100-\mathrm{msec}$ interitem interval was employed to minimize intertrial processing.

Instructions were presented on the screen. All subjects were told that the task measured "how well you can pay attention to a series of words and numbers." A target was defined and examples were given. Subjects in the intentional condition were also told that they would be tested for word frequency at the end of the list and they were told the exact frequencies that would occur. The nonspecific memory subjects were told "you will be given a memory test on the words" at the end of the list. Those in the incidental condition were given no instructions regarding a memory test.

For the test phase, which followed immediately, there were 175 items, the 140 words and 35 new " 0 " frequency words. The test list words were randomly arranged without restrictions. The words appeared one at a time on the screen above the numbers $0,1,2,4$, and 8 arranged 
in a horizontal row. Frequency estimates were made by pressing number keys on the keyboard. Hits, false alarms, and frequency estimates were recorded.

\section{RESULTS}

Table 1 shows the mean proportion of hits for numbers and words. The number of false alarms was small (164 of 231 subjects had none); therefore, only the hits were analyzed. The data were entered into a 2 (rate of presentation) $\times 3$ (instruction) $\times 2$ (target type) mixed-design analysis of variance (ANOVA), with target type serving as the repeated factor. The analysis revealed significant main effects for rate of presentation $[F(1,225)=8.68$, $p<.004, M S \mathrm{e}=.0331]$ and target type $[F(1,225)=$ $14.403, p<.001, M S e=.0102]$. The mean proportion of hits for the 1-sec rate was .871 and that for the 2 -sec rate was .919 . The hit rates for the words and numbers were .914 and .877 , respectively. The main effect for instruction was marginally significant $(p<.075)$. These means were $.899, .871$, and .916 for the intentional, nonspecific, and incidental conditions, respectively.

Instructions influenced vigilance performance in the expected direction. This was reflected in the instruction $x$ target type interaction $[F(2,225)=4.74, p<.01, M S \mathrm{e}$ $=.0102]$. The mean hit rates (word/number rate) were $.914 / .885, .908 / .835$, and $919 / .913$ for the intentional, nonspecific, and incidental conditions, respectively. In accordance with their instructions, subjects in the intentional and nonspecific conditions devoted more attention to the words than to the numbers. The incidental subjects' attention was more evenly distributed with respect to target type. There were no other significant effects.

Table 2 shows the mean frequency estimates for each group. An ANOVA of the absolute frequency estimates found an interaction effect for frequency $\times$ rate $[F(4,900)$ $=6.49, p<.0001]$ and frequency $\times$ instruction $[F(8,900)=4.80, p<.0001]$. No other effects were significant, except the frequency main effect $[F(4,900)=$ $939.06, p<.0001]$. The mean square error for these tests was 0.35 . The frequency $\times$ rate effect was due to more accurate estimates for the 2 -sec rate at frequencies 0,1 , and 2 but not at 4 and 8 . The frequency $\times$ instruction effect was due to more accurate frequency estimates by the nonspecific and intentional instruction groups than by

Table 1

Proportions of Hits for Numbers and Words

\begin{tabular}{|c|c|c|c|c|c|c|}
\hline \multirow[b]{3}{*}{ Rate } & \multicolumn{6}{|c|}{ Group } \\
\hline & \multicolumn{2}{|c|}{ Incidental } & \multicolumn{2}{|c|}{ Nonspecific } & \multicolumn{2}{|c|}{ Intentional } \\
\hline & $M$ & $S D$ & $M$ & $S D$ & $M$ & $S D$ \\
\hline \multicolumn{7}{|c|}{ Numbers } \\
\hline $1 \mathrm{sec}$ & .883 & .116 & .825 & .194 & .858 & .194 \\
\hline $2 \mathrm{sec}$ & .942 & .058 & .844 & .268 & .915 & .099 \\
\hline \multicolumn{7}{|c|}{ Words } \\
\hline $1 \mathrm{sec}$ & .883 & .115 & .899 & .119 & .877 & .204 \\
\hline $2 \mathrm{sec}$ & .954 & .052 & .916 & .103 & .956 & .040 \\
\hline
\end{tabular}

Table 2

Mean Frequency Estimates for Each Group

\begin{tabular}{ccccccccc}
\hline & \multicolumn{3}{c}{ 1-Sec Rate } & & \multicolumn{3}{c}{ 2-Sec Rate } \\
\cline { 2 - 4 } \cline { 6 - 8 } Frequency & Int. & Non. & Inc. & & Int. & Non. & Inc. & $M$ \\
\hline 0 & 1.19 & 1.17 & 1.37 & & 0.95 & 0.89 & 0.95 & 1.08 \\
1 & 1.76 & 1.70 & 1.93 & & 1.69 & 1.67 & 1.42 & 1.69 \\
2 & 2.50 & 2.32 & 2.39 & & 2.37 & 2.42 & 2.03 & 2.33 \\
4 & 2.76 & 2.88 & 2.84 & & 2.91 & 2.98 & 2.51 & 2.81 \\
8 & 4.31 & 4.20 & 3.92 & & 4.64 & 4.58 & 3.86 & 4.25 \\
\hline
\end{tabular}

Note-Int. $=$ intentional, Non. $=$ nonspecific, Inc. $=$ incidental.

Table 3

Fisher $Z$ Scores of Pearson Correlation Coefficients $(r \mathrm{~s})$ Between Actual and Estimated Frequencies

\begin{tabular}{cccccccc}
\hline & \multicolumn{9}{c}{ Group } \\
\cline { 2 - 5 } Rate & $M$ & $S D$ & & \multicolumn{2}{c}{ Incidental } & & \multicolumn{2}{c}{ Nonspecific } & & \multicolumn{2}{c}{ Intentional } \\
\cline { 2 - 5 } \cline { 5 - 8 } & $M$ & $S D$ & & $M$ & $S D$ \\
\hline $1 \mathrm{sec}$ & .420 & .233 & .506 & .167 & .514 & .206 \\
$2 \mathrm{sec}$ & .527 & .223 & .602 & .211 & .623 & .200 \\
\hline
\end{tabular}

the incidental group. Both interactions reflected small differences.

The discrimination coefficient was used as the measure of sensitivity to frequency. The Pearson $r \mathrm{~s}$ were converted to Fisher $Z$ coefficients. Table 3 presents the means and $S D$ s of the $Z$ coefficients for the six groups. An ANOVA of these data found a significant effect for rate $[F(1,225)$ $=14.23, p<.0004, M S e=.043]$ and instruction $[F(2,225)=4.66, p<.01, M S e=.043]$. The means for the 1 -sec and 2 -sec rates were .477 and .579 , respectively. Those for intentional, nonspecific, and incidental instructions were $.565, .556$, and .475 , respectively. A planned comparison yielded significant differences between the intentional and incidental conditions $[F(1,145)$ $=6.00, p<.01, M S e=0.48]$ and between nonspecific and incidental conditions $[F(1,145)=6.19, p<.01, M S \mathrm{e}$ $=.045]$. There was no interaction effect.

\section{DISCUSSION}

Our purpose was to show whether instructions affected frequency encoding under task conditions that minimized effortful, strategic processing. Despite minimal opportunities for the subjects to rehearse or use strategies, we found instructional effects similar to those that had been reported previously. Moreover, there were performance differences in the cover task that suggested a trade-off in processing. Nevertheless, our results are not entirely consistent with the view that memory for frequency is strategically encoded. It seems more likely that the effects are due to differences in the encoding of individual item attributes, rather than to memory for frequency per se.

First, the encoding of frequency was difficult. Yet subjects remembered frequency to some extent even under genuine incidental conditions. More important, although memory for frequency was statistically poorer under incidental than under intentional instructions, the differences were not large (correlations of .565 vs. .475). Second, specific instructions to remember frequency led to no better performance than did nonspecific memory instructions.

In our view, these results can best be interpreted as showing a relationship between memory for frequency information and the quality or extent of individual item encoding. Our cover task ensured attention to items. The detection of targets was dependent upon attending and remembering an item until the next one appeared. This should have en- 
sured that Hasher and Zacks's $(1979,1984)$ requirement that items must be "attended to" was met. In keeping with our hypothesis, a number of studies (Erickson \& Gaffney, 1985; Greene, 1986; Jonides \& NavehBenjamin, 1987; Naveh-Benjamin \& Jonides, 1986; Rose \& Rowe, 1976) have shown that memory for the frequency of words is much better under semantic than under nonsemantic encoding conditions. Also, Begg, Maxwell, Mitterer, and Harris (1986) concluded that frequency estimates depend on the same "cognitive stuff" as other memories. By cognitive stuff, they mean the discriminable attributes of an event. They further suggested that frequency may not be encoded as events occur but may instead be an inference dependent upon the quality of memory for individual events. This indirect coding model would seem to account for our findings: Instructions and exposure rate indirectly affect frequency estimates by affecting the quality of individual item encoding, rather than directly affecting frequency coding per se.

\section{REFERENCES}

AtTig, M., \& Hasher, L. (1980). The processing of frequency of occurrence information by adults. Journal of Gerontology, 35, 66-69.

BegG, I., MaXwell, D., Mitterer, J. O., \& Harris, G. (1986). Estimates of frequency: Attribute or attribution. Journal of Experimental Psychology: Learning, Memory \& Cognition, 12, 496-508.

Erickson, J. R., \& GAFFNEY, C. R. (1985). Effects of instructions, oricnting task, and memory tests on memory for words and word frequency. Bulletin of the Psychonomic Society, 23, 377-380.

FiSK, A. D., \& SCHNEIDER, W. (1984). Memory as a function of attention, level of processing, and automatization. Journal of Experimental Psychology: Learning, Memory, and Cognition, 10, 181-197.

FLEXER, A. J., \& Bower, E. H. (1975). Further evidence regarding instructional effects of frequency judgments. Bulletin of the Psychonomic Society, 6, 321-324.
Greene, R. L. (1984). Incidental learning of event frequency. Memory \& Cognition, 12, 90-95.

GREENE, R. L. (1986). Effects of intentionality and strategy on memory for frequency. Journal of Experimental Psychology: Learning, Memory \& Cognition, 12, 489-495.

Hasher, L., \& Chromiak, W. (1977). The processing of frequency information: An automatic mechanism. Journal of Verbal Learning \& Verbal Behavior, 16, 173-184.

HASHER, L., \& ZACKS, R. T. (1979). Automatic and effortful processes in memory. Journal of Experimental Psychology: General, 108, 356-388.

HASHER, L., \& ZACKS, R. T (1984). Automatic processing of fundamental information. American Psychologist, 39, 1372-1388.

JoNides, J., \& NAVEH-BENJAMIN, M. (1987). Estimating frequency of occurrence. Journal of Experimental Psychology: Learning, Memory, \& Cognition, 13, 230-240.

Kausler, D. H., \& Puckett, J. M. (1980). Frequency judgments and correlated cognitive abilities in young and elderly adults. Journal of Gerontology, 35, 376-382.

Naveh-Benjamin, M., \& Jonides, J. (1986). On the automaticity of frequency coding: Effects of competing task load, encoding strategy, and intention. Journal of Experimental Psychology: Learning, Memory, \& Cognition, 12, 378-386.

Rose, R. J., \& RowE, E. J. (1976). Effects of orienting task and spacing of repetitions on frequency judgments. Journal of Experimental Psychology: Human Learning \& Memory, 2, 142-152.

ThoRndiKe, E. L., \& LoRGE, I. (1944). The teacher's word book of 30,000 words. New York: Teachers College Press.

Zacks, R. T., Hasher, L., \& SANFT, H. (1982). Automatic encoding of event frequency: Further findings. Journal of Experimental Psychology: Learning, Memory, \& Cognition, 8, 106-116.

(Manuscript received for publication September 5, 1987.) 